\title{
Identification of modal strains in concrete beams at sub-microstrain amplitude excitation using fibre Bragg grating sensors mounted on a strain amplifying transducer
}

\author{
Urszula Nawrot ${ }^{1}$, Ben De Pauw ${ }^{1}$, Dimitrios Anastasopoulos ${ }^{2}$, Edwin Reynders², Guido De Roeck², \\ Francis Berghmans ${ }^{1}$, Thomas Geernaert ${ }^{1}$ \\ ${ }^{1}$ Brussels Photonics (B-PHOT), Vrije Universiteit Brussel and Flanders Make, Dept. of Applied Physics and Photonics, \\ Pleinlaan 2, B-1050 Brussels, Belgium \\ ${ }^{2}$ University of Leuven (KU Leuven), Department of Civil Engineering, Structural Mechanics Section, Kasteelpark Arenberg \\ 40 - bus 2448, B-3001 Leuven, Belgium \\ E-mail: thomas.geernaert@vub.be
}

\begin{abstract}
Vibration-based damage identification is a non-destructive method that enables health monitoring of civil infrastructures. It aims to detect the presence and location of damage by measuring changes in the vibration characteristics of these structures. Unfortunately, the most popular vibrational parameters - natural frequencies and modal displacements - have a low sensitivity to certain types of local damage. Modal strains and curvatures, on the other hand, can be sufficiently sensitive to local damage but monitoring modal strains is challenging. Indeed, the strain amplitudes can be in the sub-microstrain range $(<1 \mu \varepsilon)$ when considering ambient excitation which is too small for most conventional techniques. Here we show that such measurements can be successfully carried out in a quasi-distributed manner with fibre Bragg grating based sensors that have been mounted on a dedicated strain amplifying transducer. First, we report on lab-scale dynamic tests on a $5 \mathrm{~m}$ long concrete beam, equipped with such transducers having a strain amplification of 62. Our results show that we can identify the first 3 bending modes while the average strain level on the beam was only $0.06 \mu \varepsilon$. Second, we present the first field test for these transducers conducted on a highspeed railway viaduct. We have succeeded to obtain 6 strain modes of the viaduct from the data collected with the FBGs on the transducers under an average strain level of $0.067 \mu \varepsilon$. To the best of our knowledge this is the first time that strain mode identification in operational conditions using strain amplifying transducers was successful. This demonstration can be a starting point for the implementation of vibrationbased damage identification in civil structures allowing the fulfilment of its long-standing promise.
\end{abstract}

\section{Introduction}

Vibration-based structural health monitoring (VBSHM) is a non-destructive condition assessment method, based on the identification of changes in the dynamic characteristics of a structure (natural frequency, modal damping and mode shapes), which are directly related to damage. While other nondestructive testing or evaluation methods typically serve either local or global damage assessment strategies, VBSHM provides an interesting alternative as it potentially allows for detecting and locating the occurrence of damage in an overall structure.

The modal parameters of a structure can be obtained from a forced or ambient vibration test on a structure by using system identification methods [1]. To assess damage from the extracted modal parameters, several methods have been proposed: the natural frequency-based method, the displacement mode shape-based method and the curvature/strain mode shape-based method [2]. Natural frequencies are however also influenced by environmental factors, such as temperature. Their influence can be sufficient to completely mask the presence of even severe damage [3]. This first method also suffers from a low sensitivity to certain types of damage, especially to local damage of moderate severity [4]. Modal characteristics obtained from dynamic strain measurements, on the other hand, are more 
sensitive to local damage [5], [6], [7]. Strain mode shape based methods would thus be an attractive first choice. However the very small strain levels at which such modes vibrate when considering ambient or operational excitation in typical concrete civil structures are an obstacle. The current challenge in VBSHM relying on strain modes is therefore to develop a monitoring system that is sufficiently sensitive to local damages, that can be easily mounted over an extended structure and that is cost-effective.

Strain measurements conventionally rely on the use of electrical strain gauges. These sensors are wellknown and widely commercially available. However, strain gauges are also known to feature a limited strain sensitivity around $\sim 1 \mu \varepsilon$, to suffer from drift, to be sensitive to moisture and to electromagnetic interference (EMI). Alternatively, fibre Bragg grating (FBG) based strain sensors are increasingly used for SHM applications owing to their low weight, small size, ability to operate in harsh environments and multiplexing capabilities [8].

An FBG is formed by a periodic modulation of the refractive index in the core of a single mode optical fibre. When broadband light travels along the FBG, only wavelengths within a narrow spectral band are reflected. The central wavelength of this band is called the Bragg wavelength and is given by

$$
\lambda_{B}=2 n_{\mathrm{eff}} \Lambda
$$

where $n_{\text {eff }}$ is the effective refractive index and $\Lambda$ is the period of a grating. The multiplexing capabilities of FBG sensors enable monitoring of civil structures with a large number of sensors in a dense grid, which facilitates the identification of local damage. FBG sensors have already been used, for example, for real-time monitoring of railway infrastructure [9] and bridge structures [10], [11] but these methods required artificial excitation. When a fibre Bragg grating is subjected to strain, the Bragg wavelength changes proportionally to the strain. FBGs in silica optical fibres typically feature a strain sensitivity of $1.2 \mathrm{pm} / \mu \varepsilon$. This dependency allows determining the strain from the reflected FBG wavelength. Practically, most FBG interrogators can determine the Bragg wavelength with a resolution of about 1 $\mathrm{pm}$, which results in a strain measurement resolution of $1 \mu \varepsilon$. Despite their appealing advantages, an increase of their sensitivity by at least an order of magnitude is required before enabling VBSHM relying on strain modes.

In this context, the ability to identify the modal characteristics of a structure, based on dynamic submicrostrain measurements with FBG sensors, has been recently explored. A first option is the combination of a conventional spectrometer-like interrogator with an advanced wavelength-shift detection algorithm [12], which allows to increase the sensitivity with about a factor of 3. A second option is to interrogate the FBGs with a very high wavelength resolution, for example with a tuneable laser in sufficiently small wavelength steps. This is often followed by a synchronization step to account for the time differences between the measurement of different wavelength multiplexed sensors [6]. The option explored here is to rely on mechanical strain amplification, which can be combined with any FBG interrogator. Strain amplifying transducers such as the one used here are primarily intended for structural health monitoring of large and stiff structures such as civil engineering structures (bridges, dams, tunnels, etc.). Its relatively large dimensions allow upscaling of the average strain over a certain 'gage length'. As such its strain measurements can be considered as amplified values of the 'macro' strain. This approach therefore makes most sense in very stiff structures with very low ambient strain levels.

The lab and field test reported here are the first successful strain mode shape identifications of concrete beams in operational conditions based on the measurements of a linear array of FBG sensors on strain amplifying transducers. 
The paper is structured as follows. First, we describe the strain-amplifying transducer and its strain sensitivity in section 2 . In section 3 the lab-scale dynamic test on a 5-m long pre-stressed concrete beam equipped with our transducers is described and the performance is compared with that of regular FBGs directly clamped to the structure. The results of the transducer-based approach of a field test on a highspeed railway viaduct are reported in section 5. A summary and conclusions make section 6 .

\section{Strain mode identification on a laboratory prestressed concrete beam}

\subsection{Mechanical strain amplifying transducer}

To enable the identification of strain mode shapes at sub-microstrain strain amplitudes we implemented the strain transducer described in [13], with adapted dimensions. The size of the transducers is $244 \mathrm{~mm}$ by $105 \mathrm{~mm}$, with an effective gauge length of $204 \mathrm{~mm}$. They are equipped with two holes that allow attaching the system to the concrete beam, or to any other structure (see Figure 1). The strain amplification $\mathrm{A}$ is defined as:

$$
A=\frac{\varepsilon_{\mathrm{f}}}{\varepsilon_{\mathrm{t}}}=\frac{\Delta L_{\mathrm{f}} / L_{\mathrm{f}}}{\Delta L_{\mathrm{t}} / L_{\mathrm{t}}}
$$

where $L_{\mathrm{f}}$ is the distance over which the FBG measures the amplified strain, and $L_{\mathrm{t}}$ is the distance over which the reference FBG measures strain between mounting holes. The FBG sensors mounted on these transducers are commercially available ORMOCER ${ }^{\circledR}$ coated draw tower gratings $\left(\mathrm{DTG}{ }^{\circledR}\right)[16]$. The simulations explained in [13], return a strain amplification of 61 . The first calculated natural frequency of the transducer is $353 \mathrm{~Hz}$, which is higher than the first three bending natural frequencies of the concrete beam $(37.7 \mathrm{~Hz}, 98.8 \mathrm{~Hz}, 192.4 \mathrm{~Hz})$ as described in the next section.

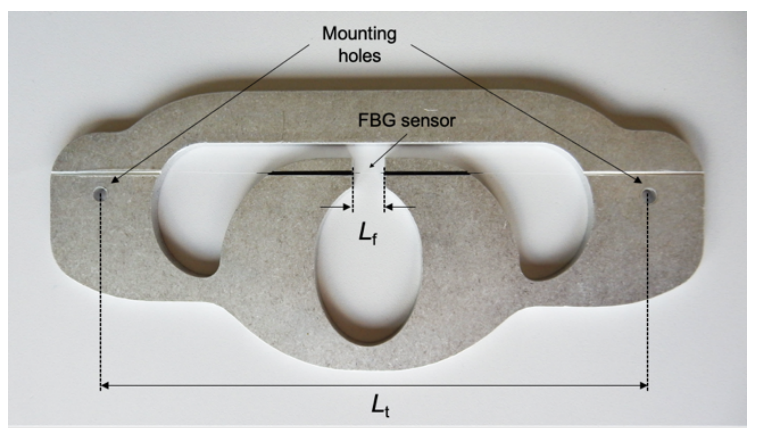

Figure 1: Photograph of the fabricated transducer with indication of the location of the FBG sensor $(244 \times 105) \mathrm{mm}$.

32 transducers equipped with FBG sensors were produced. The average amplification value was 62 , with a standard deviation of 1.9, which agrees well with the simulated value. Using the transducer and counting on a strain amplification factor of 62 , in principle a strain resolution of about $0.01 \mu \varepsilon$ can be achieved using a conventional broadband FBG interrogator with a wavelength resolution of $1 \mathrm{pm}$.

\subsection{Experimental setup and strain measurements}

Experiments were conducted on a prestressed concrete beam. The beam is $5 \mathrm{~m}$ long and has a cross section of $240 \times 200 \mathrm{~mm}^{2}$. The dynamic boundary conditions approximate those of a free-free vibrating beam. This is achieved with the use of inflated tyres as supports, as illustrated in Figure 2. 


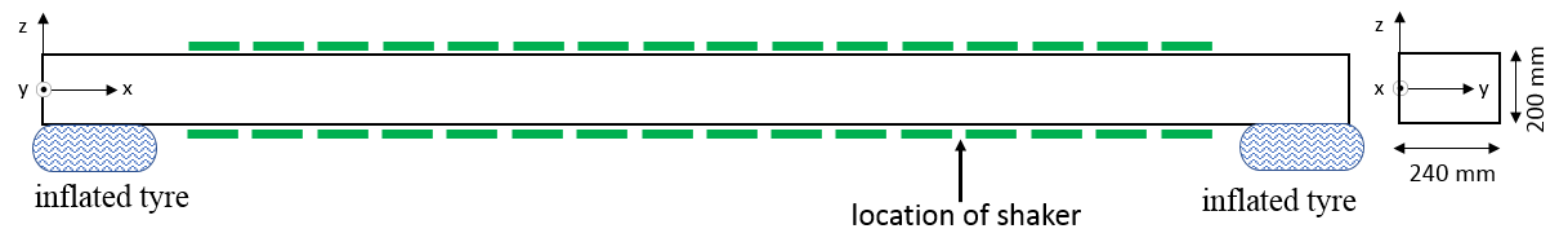

Figure 2. Experimental setup of dynamic test on prestressed concrete beam. The green lines indicate the location of the transducers at the top and the bottom of the beam.

Two chains of 16 FBGs on mechanical strain amplifying transducers are attached at the top and the bottom of the beam to measure the axial dynamic strains, as shown in Figure 3 (a) and (b). The transducers on the prestressed concrete beam are mounted on dedicated mounting supports (see Figure 4). We glued them to the surface of the beam using X60 adhesive from HBM [16]. The centre-to-centre distance between two subsequent sensors was $0.25 \mathrm{~m}$.

Also two chains of 20 DTG sensors are attached at the beamside (see Figure 3(c)) with the same sensorto-sensor distance. Those sensor fibres were mounted with clamps (see Figure 4(b)), that have been introduced in [6]. Such installation allows measuring the average strain with a gauge length comparable to that of the transducers.

a)

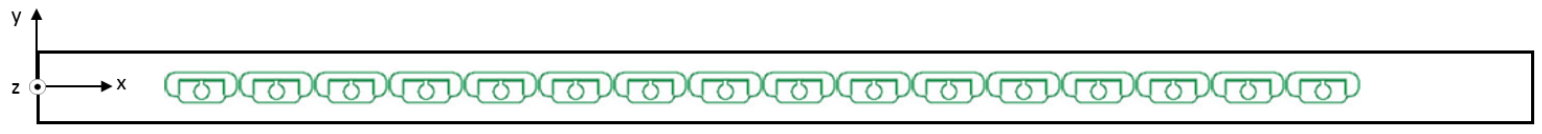

b)

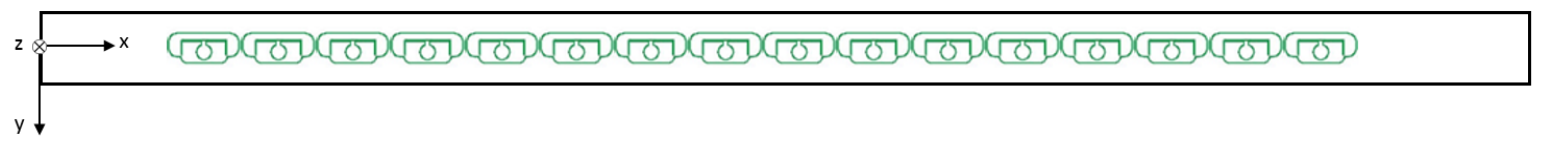

c)

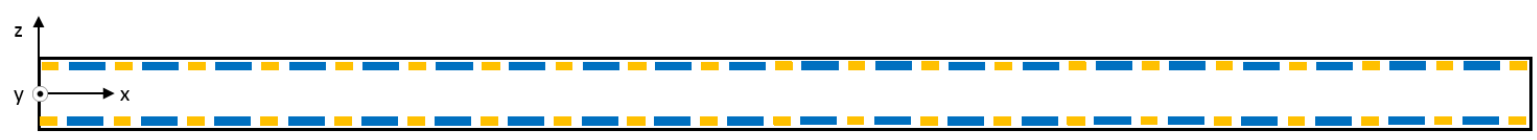

Figure 3: (a,b) Beam equipped with 32 strain amplifying transducers - top and bottom view and (c) side view with 20 regular FBG sensors: the blue dashes indicate the FBG sensors and the yellow dots indicate the location of the clamps (see also Figure 4 b).

a)

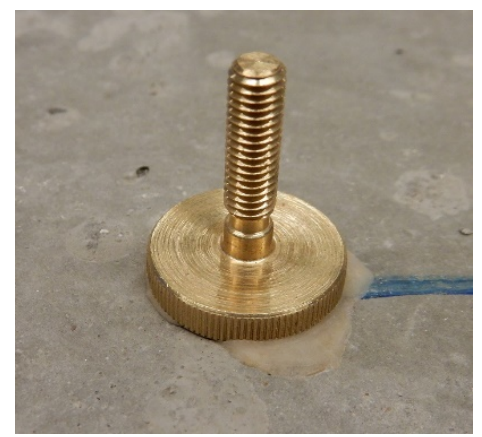

b)

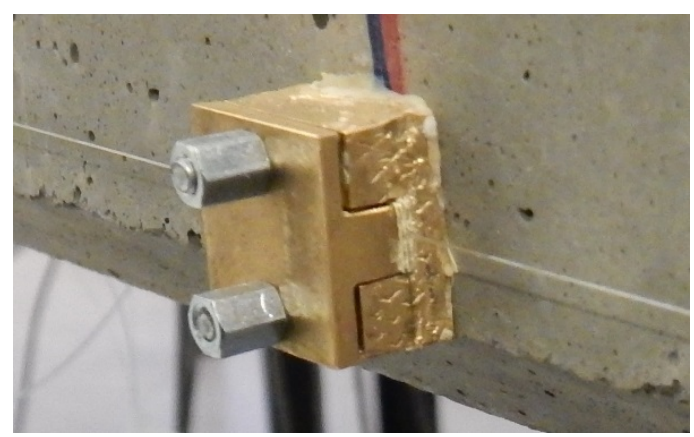

Figure 4: (a) Photo of the mounting support for the strain amplifying transducer and (b) clamps for the regular FBG strain sensors. 
The concrete beam is excited vertically with an electrodynamic shaker located in $\mathrm{x}=4 \mathrm{~m}$ (see also Figure 2), using force amplitudes with RMS values of $10 \mathrm{~N}$ and $130 \mathrm{~N}$. The excitation signals were swept sines in the range $[0: 400] \mathrm{Hz}$ with a total sweep time of $15 \mathrm{~s}$. To record the Bragg peak wavelength shifts and derive the strain measurements, a broadband FBG-scan 704D acquisition system [14] was used together with its built-in peak detection algorithm. Figure 5 (a) illustrates the strain obtained with a selected transducer during the first dynamic test with a force amplitude of $10 \mathrm{~N}$ (all other transducers return similar results). As expected, the strain measured by the FBG on the transducer is larger than that recorded by the clamped FBG strain sensor at an equivalent position along the beam (Figure 5 (b)). The maximum strain recorded with the first was $\sim 4 \mu \varepsilon$, while that obtained by the latter was below the noise level.

Figure 6 shows the strain versus time obtained with sensors at an equivalent position along the beam during the second dynamic test with a force amplitude of $130 \mathrm{~N}$. The maximum strain measured by the FBGs on the transducers was now $\sim 50 \mu \varepsilon$ (Figure 6 (a)). Considering the strain amplification value of 61 , the strain values experienced by the clamped FBGs will still be about $1 \mu \varepsilon$ or less, as reflected by the binary nature of the measurements shown in Figure 6 (b). The strain variation measured by the clamped FBG nevertheless shows a fluctuation up to $2.5 \mu \varepsilon$ which is most likely attributed to a local temperature change.

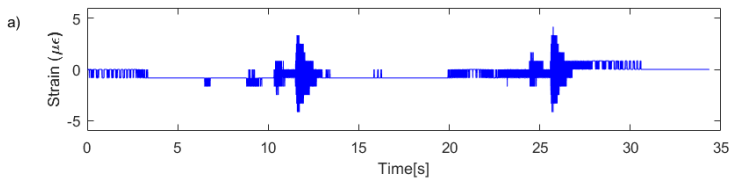

b)

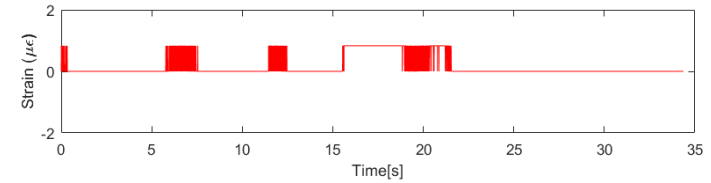

Figure 5: Strain measurements during dynamic tests with a force amplitude of $10 \mathrm{~N}$ recorded with (a) an FBG mounted on a transducer and (b) an FBG directly clamped to the beam.
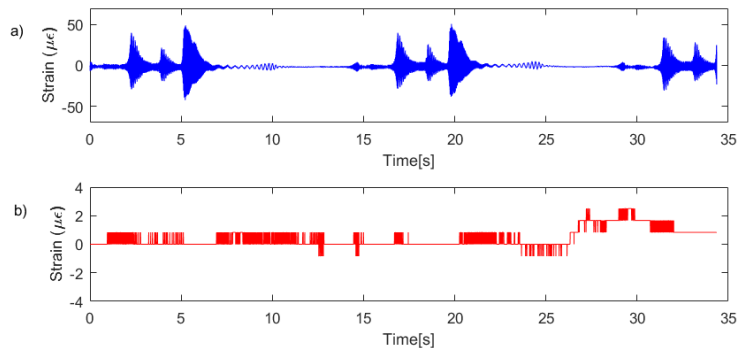

Figure 6: Strain measurements during dynamic tests with a force amplitude of $130 \mathrm{~N}$ recorded with (a) an FBG mounted on a transducer and (b) an FBG directly clamped to the beam.

\subsection{Simulated modal analysis}

As a reference point for the modal analysis the beam was simulated in COMSOL $₫$ [15]. This model took into account the 7-wire low relaxation strands with a nominal diameter of $12.5 \mathrm{~mm}$ that were used for prestressing the beam ( 3 at the bottom and 2 at the top), as well as the closed-loop stirrups, with a nominal diameter of $6 \mathrm{~mm}$ and a centre-to-centre distance of $150 \mathrm{~mm}$, which were incorporated to withstand the shear forces. The FE mesh contains a total of 20403 elements (tetrahedral and triangles). We used the material parameters summarized in Table 1 and we applied free-free boundary conditions as in the actual experiment. Note that the dynamic Young's modulus for concrete was calculated based on the ASTM C215 standard [17]. Table 2 reports the calculated natural in the bandwidth of interest, [0:400] Hz. Figure 7 shows the displacement mode shapes of first three vertical bending modes, as computed from the finite element model.

Table 1. Material properties used in the COMSOL ${ }^{\circledR}$ FE model of the concrete beam.

\begin{tabular}{lll}
\hline Material & Young's Modulus (E) & Density $(\boldsymbol{\rho})$ \\
\hline Concrete & $48 \mathrm{GPa}$ & $2400 \mathrm{~kg} / \mathrm{m}^{3}$ \\
\hline Steel & $210 \mathrm{GPa}$ & $7850 \mathrm{~kg} / \mathrm{m}^{3}$ \\
\hline
\end{tabular}


Table 2. Natural frequencies calculated from the concrete beam's FE model and obtained from the experiment.

\begin{tabular}{cccc}
\hline Mode & Type & $\begin{array}{c}\text { Natural } \\
\text { frequency } \\
\text { (FE model) }\end{array}$ & $\begin{array}{c}\text { Natural frequency } \\
\text { (Experiment) }\end{array}$ \\
\hline 1 & Vertical bending mode 1 & $\mathbf{3 6 . 8 ~ H z}$ & $\mathbf{3 7 . 7}$ \\
\hline 2 & Lateral mode 1 & $43.8 \mathrm{~Hz}$ & - \\
\hline 3 & Vertical bending mode 2 & $\mathbf{1 0 0 ~ H z}$ & - \\
\hline 4 & Lateral mode 2 & $119 \mathrm{~Hz}$ & $\mathbf{1 9 2 . 4}$ \\
\hline 5 & Vertical bending mode 3 & $\mathbf{1 9 4 ~ H z}$ & - \\
\hline 6 & Lateral mode 3 & $229 \mathrm{~Hz}$ & - \\
\hline 7 & Torsional mode 1 & $266 \mathrm{~Hz}$ & - \\
\hline 8 & Bending mode 4 & $315 \mathrm{~Hz}$ & \\
\hline 9 & Lateral mode 4 & $369 \mathrm{~Hz}$ & \\
\hline
\end{tabular}

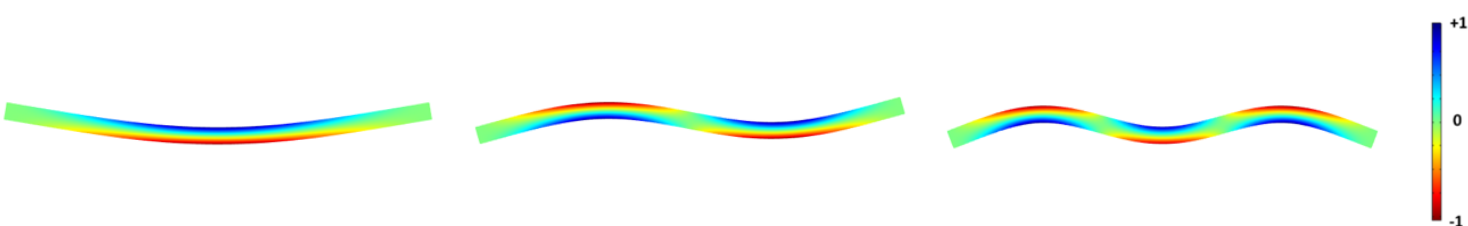

(a)

(b)

(c)

Figure 7: Calculated strain mode shapes of the beam for the first $-36.8 \mathrm{~Hz}$ (a), second $-100 \mathrm{~Hz}$ (b) and third $-194 \mathrm{~Hz}$ (c) vertical bending mode simulated with COMSOL ${ }^{\circledR}$. The colour scale covers normalized strain levels from -1 to +1 .

\subsection{Extraction of the modal strains from the strain measurement data}

For system identification MACEC, a Matlab ${ }^{\circledR}$ toolbox for experimental and operational modal analysis was used [19]. For large civil structures one mostly uses output-only modal analysis and therefore we did not use the shaker force. We applied the covariance-driven Stochastic Subspace Identification (SSIcov), which is an output-only time domain identification technique [19], [20]. The SSI-cov algorithm also provides the $95 \%$ confidence intervals $([-2 \sigma, 2 \sigma])$ for quantifying the uncertainty of the identified dynamic characteristics. The model order is chosen in steps of 2 and the maximum order is 60 . The half number of Hankel block rows $i$ is 50 . The number of data blocks for the calculation of the variance of the output correlation estimates $\sigma$ is set to $n=200$. We remove the static or Direct Current (DC) offset from all measured signals and we apply a fourth-order Butterworth filter with a high-pass frequency of $4 \mathrm{~Hz}$ to all channels to remove the influence of small temperature fluctuations on the Bragg wavelength of the FBG sensors, and thus on the strain measurements.

Figure 8 and Figure 9 show the mode shapes of the first three vertical bending modes of the beam obtained from the SSI-cov identification applied to our measurements and the mode shapes obtained from FE simulations. We use a least squares fit to scale the mode shapes obtained from the experiments. Note that the measured mode shapes do not fit perfectly with the calculate bending modes. This deviation most likely results from a variation in the actual strain amplification value between the different strain transducers, as a result from variations in the mounting of the transducers on the beam. 
Figure 8 (left) shows that we could only identify two bending modes with the regular clamped FBG strain sensors with a force amplitude of $10 \mathrm{~N}$. However, the data from the FBGs on the transducers allow identifying the first three bending modes, as shown in Figure 8 (right). Figure 9 (left) and Figure 9 (right) show three bending modes obtained with the regular clamped FBG strain sensors and with the FBGs on the transducers with a force amplitude of $130 \mathrm{~N}$. To compare the quality of the mode identification obtained with the regular clamped FBG strain sensors and with the FBGs on the transducers, the Modal Assurance Criterion (MAC) is calculated, which is a criterion that quantifies the correlation between the mode shapes returned by the experiments with those revealed by the simulations. The results for both tests with excitation amplitudes of $10 \mathrm{~N}$ and $130 \mathrm{~N}$ are summarized in Table 3. The MAC values obtained using the transducers are systematically higher than those based on the regular clamped FBGs.
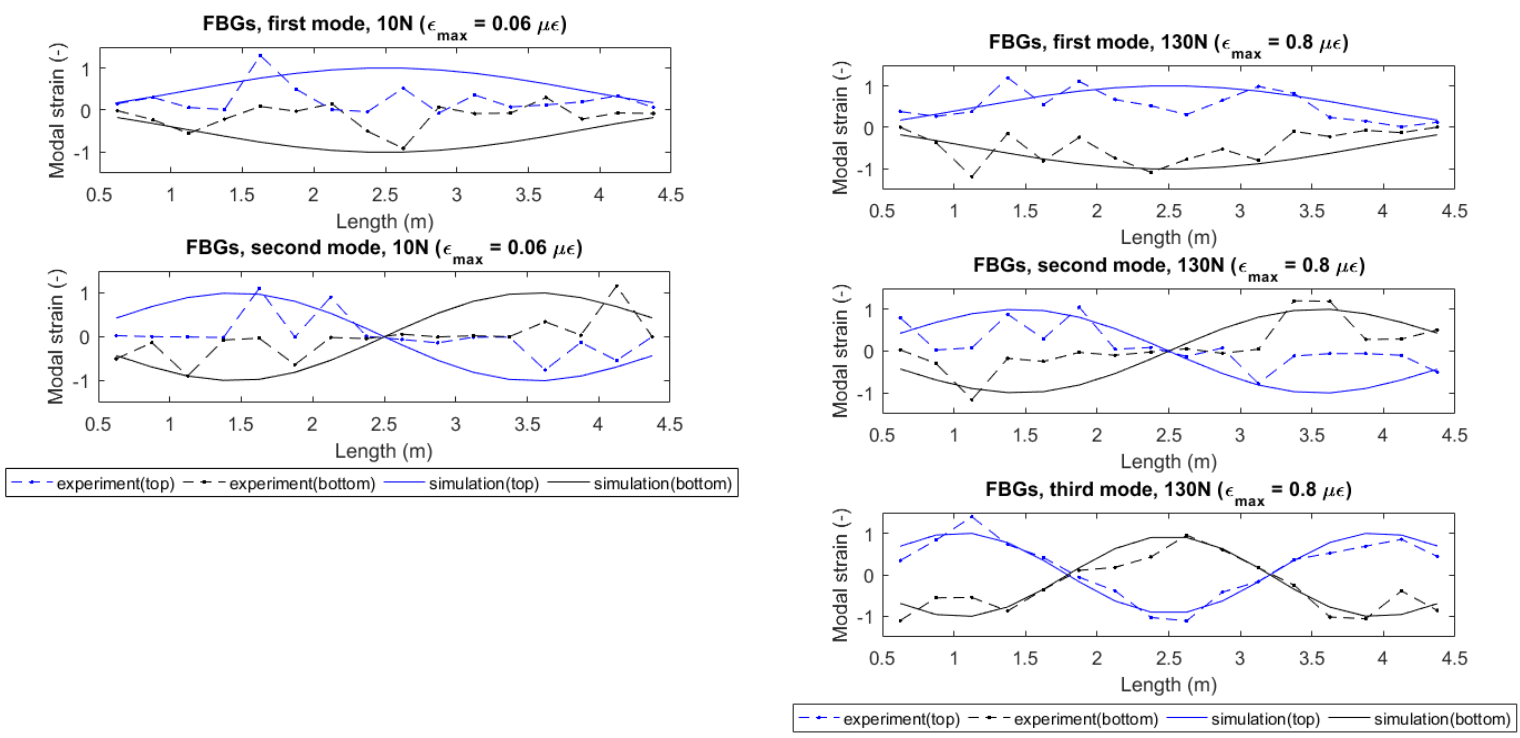

Figure 8: Modal strain shape of the bending modes excited with a force amplitude of $10 \mathrm{~N}\left(\varepsilon_{\max }=0.06 \mu \varepsilon\right)$ as measured with the regular clamped FBGs (left) and with the FBGs mounted on strain amplifying transducers (right). The vertical axis shows the normalized strain with a least squares fit measured by the successive FBG sensors along the beam at positions as indicated on the horizontal axis.
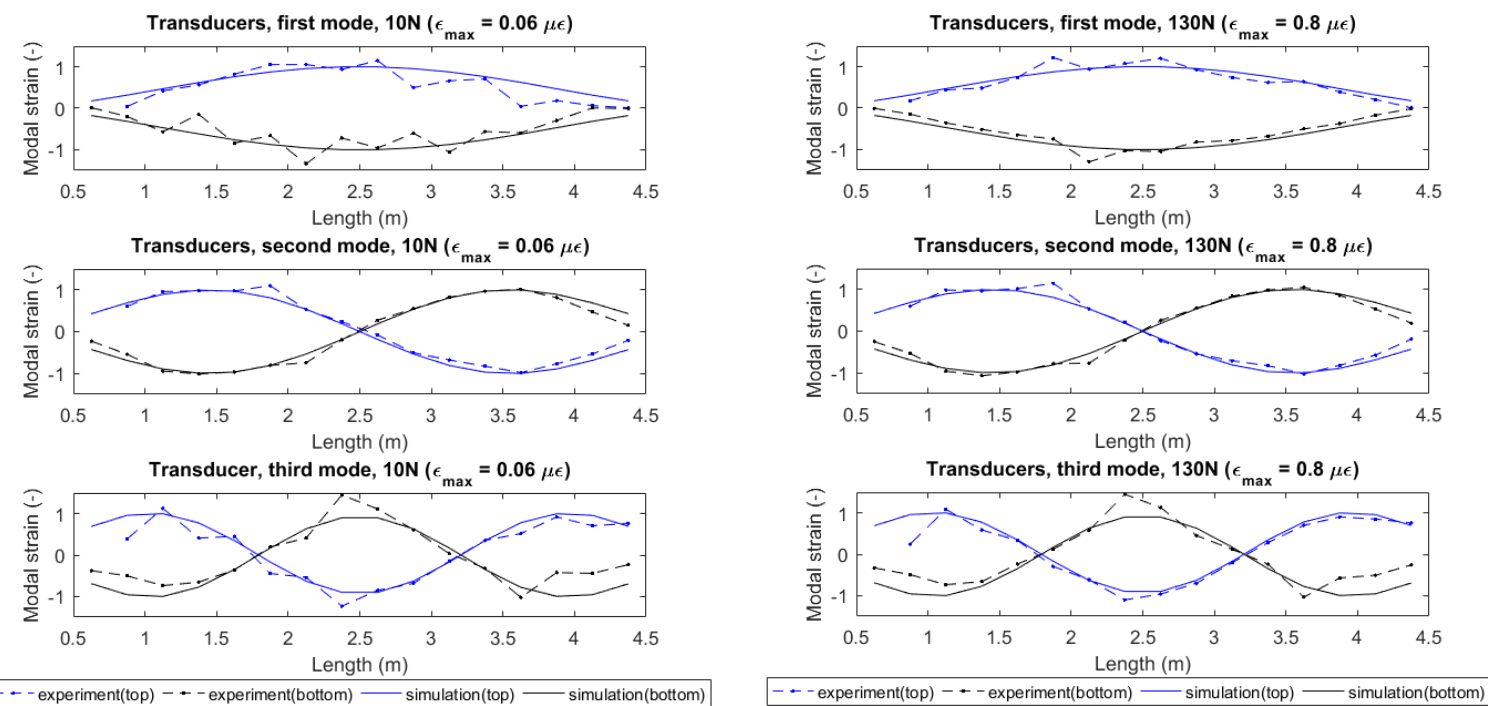

Figure 9: Modal strain shapes of the bending modes excited with a force amplitude of $130 \mathrm{~N}\left(\varepsilon_{\max }=0.8 \mu \varepsilon\right)$ as measured with the regular clamped FBGs (left) and with the FBGs mounted on strain amplifying transducers (right). 
The vertical axis shows the normalized strain with a least squares fit measured by the successive FBG sensors along the beam at positions as indicated on the horizontal axis.

Table 3: Modal Assurance Criterion values between the mode shape returned by the experiment and that obtained with simulations for an $10 \mathrm{~N}$ and $130 \mathrm{~N}$ excitation amplitudes

\begin{tabular}{ccccc}
\hline & \multicolumn{2}{c}{$\begin{array}{c}\text { Excitation amplitude 10N } \\
\left(\varepsilon_{\max }=\mathbf{0 . 0 6} \boldsymbol{\mu \varepsilon}\right) .\end{array}$} & \multicolumn{2}{c}{$\begin{array}{c}\text { Excitation amplitude 130N } \\
\left(\boldsymbol{\varepsilon}_{\max }=\mathbf{0 . 8} \boldsymbol{\mu \varepsilon}\right)\end{array}$} \\
\hline & $\begin{array}{c}\text { Clamped } \\
\text { FBGs }\end{array}$ & $\begin{array}{c}\text { FBGs on } \\
\text { transducers }\end{array}$ & Clamped FBGs & $\begin{array}{c}\text { FBGs on } \\
\text { transducers }\end{array}$ \\
\hline $\mathbf{1}^{\text {st }}$ mode & 0.113 & 0.858 & 0.559 & 0.956 \\
\hline $\mathbf{2}^{\text {nd }}$ mode & 0.577 & 0.989 & 0.705 & 0.989 \\
\hline $\mathbf{3}^{\text {rd }}$ mode & - & 0.940 & 0.929 & 0.952 \\
\hline
\end{tabular}

\section{Strain mode identification on a span of a railway viaduct}

\subsection{Description of the field test preformed on the Arbre viaduct}

The Arbre viaduct (see Figure 10) is a railway bridge located near Ath in the southwest of Belgium. It is a multi-span concrete girder bridge with 36 spans $(9 \times 63 \mathrm{~m}$ and $27 \times 53 \mathrm{~m})$ and with a total length of $2 \mathrm{~km}$ [21]. The bridge is prestressed and has a U-shape. Two side corridors allow for disaster evacuation and for maintenance (see Figure 11). This structure is particularly challenging for strain mode identification given its very high stiffness. Our measurements were conducted on the 30th span (see Figure 12).

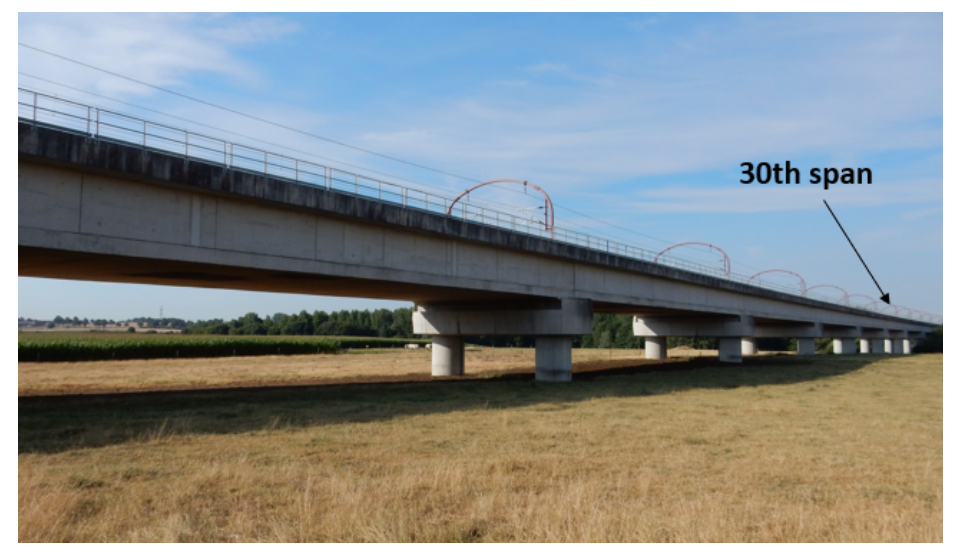

Figure 10: View of the Arbre viaduct showing span 30 to 35.

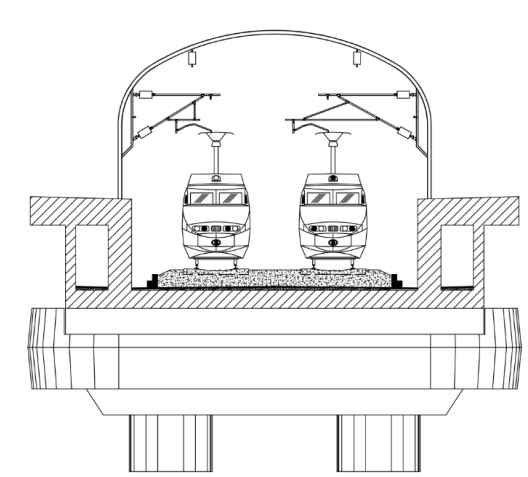

Figure 11: U-shaped cross-section of the Arbre viaduct. 


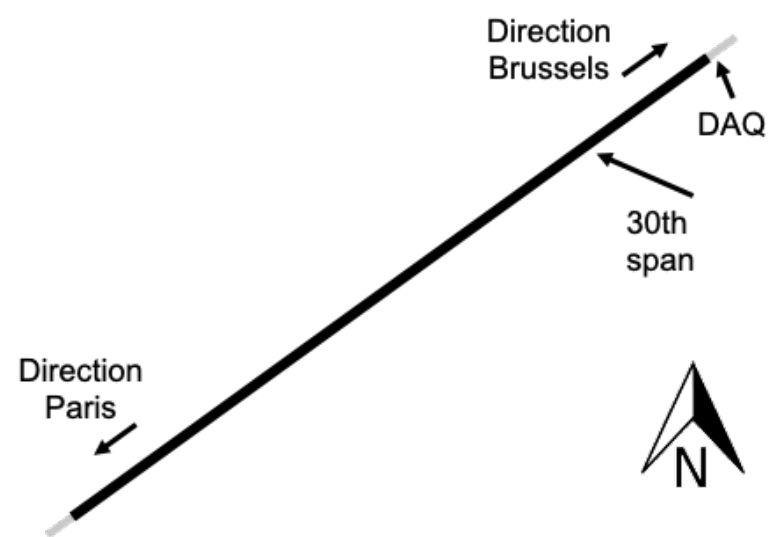

Figure 12: Schematic representation of the orientation of the Arbre viaduct, and location of the instrumented 30th span.

For the field test on the Arbre viaduct the dimensions of the transducer were resized to $360 \mathrm{~mm}$ by 105 $\mathrm{mm}$, with an effective gauge length of $320 \mathrm{~mm}$. The simulated strain amplification was 84.5. The first natural frequency of this transducer, as obtained from simulations, was $223 \mathrm{~Hz}$ which is well above the first resonance frequency of the Arbre viaduct at $3.4 \mathrm{~Hz}$. Twenty transducers were manufactured according to the design shown in Figure 13. The experimental calibration resulted in an average strain amplification of 80 with a standard deviation of 2 .

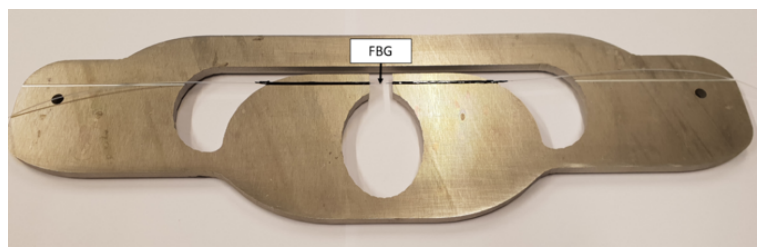

Figure 13: Transducer $(360 \times 105 \mathrm{~mm})$ with indication of the location of the FBG sensor.

We attached the 20 mechanical strain amplifying transducers equipped with a wavelength-multiplexed chain of 20 DTGs at a height of $20 \mathrm{~cm}$ above the bottom of the corridor along the length of the span to measure dynamic strains in the $\mathrm{x}$-direction, as shown in Figure 14. To mount the transducers on the concrete wall, washers were glued at the back of the transducers. This allowed installation of the transducers at the surface of the wall using X60 adhesive from HBM. Each transducer was protected from dust or abrupt temperature changes with a styrofoam box (see Figure 15 (a)). The centre-to-centre distance between two subsequent sensors was around $2.5 \mathrm{~m}$. We also attached two chains of 20 wavelength-multiplexed DTGs packaged in a ruggedized Glass Fibre Reinforced Polymer (GFRP) coating, to the top and bottom of the concrete wall (see Figure 15 (b)). The strain measurement wires were mounted with clamps, as explained in [6]. The distance between two subsequent DTG sensors is the same as the distance between the transducers $(2.5 \mathrm{~m})$. 
a)

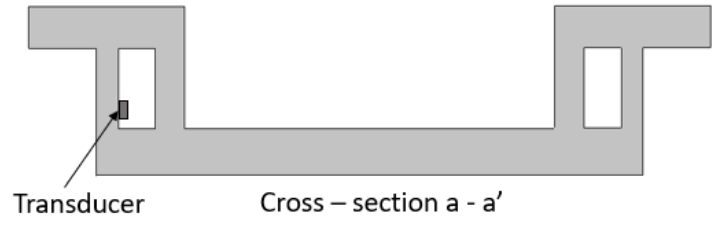

b)

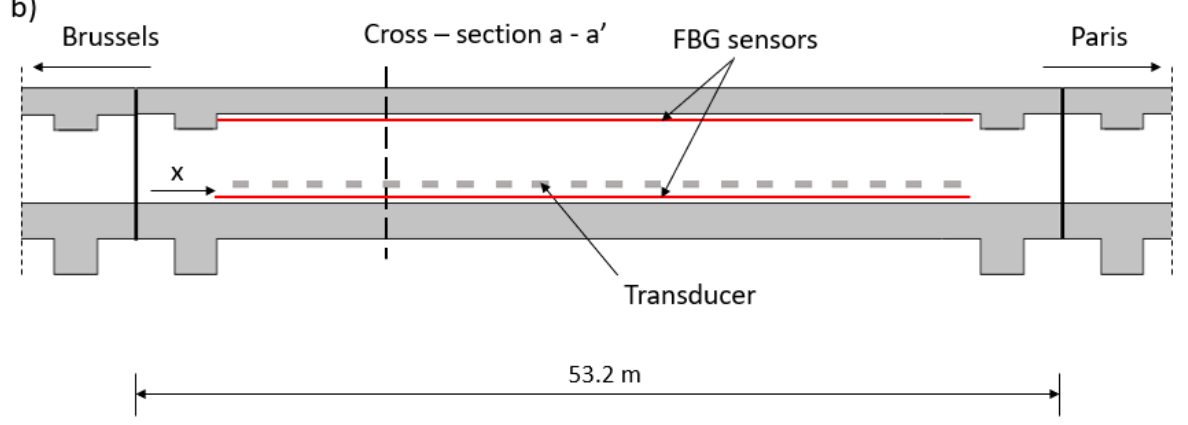

Figure 14: (a) Cross-section and (b) longitudinal section of the Arbre viaduct, including location of FBG sensors and strain amplifying transducers.

The data acquisition system was located at the end of the viaduct. Therefore, a ruggedized telecom cable of $350 \mathrm{~m}$ was used with standard single mode fibres (9/125) to connect the 3 FBG sensor chains to the interrogator. For the field test the FAZT-I4 interrogator [22] was used, which features higher wavelength precision $(<0.1 \mathrm{pm})$.

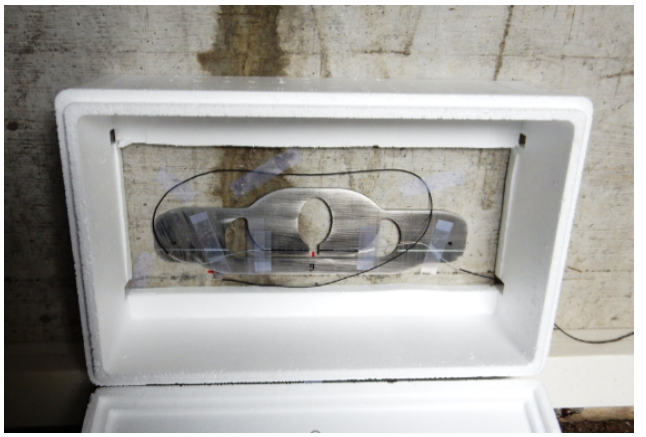

a)

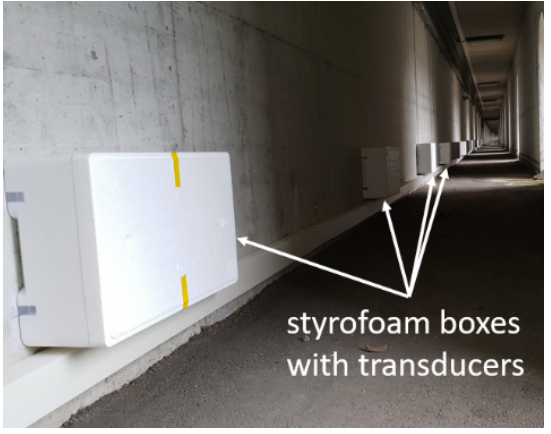

b)

Figure 15: (a) mounted transducer inside styrofoam box (b) view along the length of the whole span.

\subsection{Modal Strain Identification of a concrete span at the Arbre viaduct Under Ambient Excitation}

The experiment was performed on the $24^{\text {th }}$ October. A 15 -minute measurement was carried out under ambient excitation at a sampling frequency of $1000 \mathrm{~Hz}$ using the FAZT-I4 interrogator. The temperature outside was $16^{\circ} \mathrm{C}$ and the direction of the windspeed $(16 \mathrm{~km} / \mathrm{h}$ ) was northwest (perpendicular to the viaduct, see Figure 12Figure 12). The DTGs mounted on the transducers allowed to identify 6 natural frequencies as summarized in Table 4. Note that their type was determined from a separate experiment with wireless triaxial accelerometers. That same day, the DTG chains mounted with clamps allowed to identify only the natural frequency of the first lateral mode. The obtained strain mode shapes of the viaduct derived from the DTGs on the transducers are shown in Figure 16. The averaged root mean square strain value of these measurements was $0.067 \mu \varepsilon$ for the strain in the viaduct. 


\begin{tabular}{ccc}
\hline 1 Mode & Vertical bending mode 1 & - \\
\hline 2 Mode & Lateral bending mode 1 & $3.94 \mathrm{~Hz}$ \\
\hline 3 Mode & Torsional bending mode 1 & $4.43 \mathrm{~Hz}$ \\
\hline 4 Mode & Bending mode of the deck 1 & $6.91 \mathrm{~Hz}$ \\
\hline 5 Mode & - & $7.30 \mathrm{~Hz}$ \\
\hline 6 Mode & - & $8.22 \mathrm{~Hz}$ \\
\hline 7 Mode & - & $9.44 \mathrm{~Hz}$ \\
\hline 8 Mode & Vertical bending mode 2 & - \\
\hline
\end{tabular}
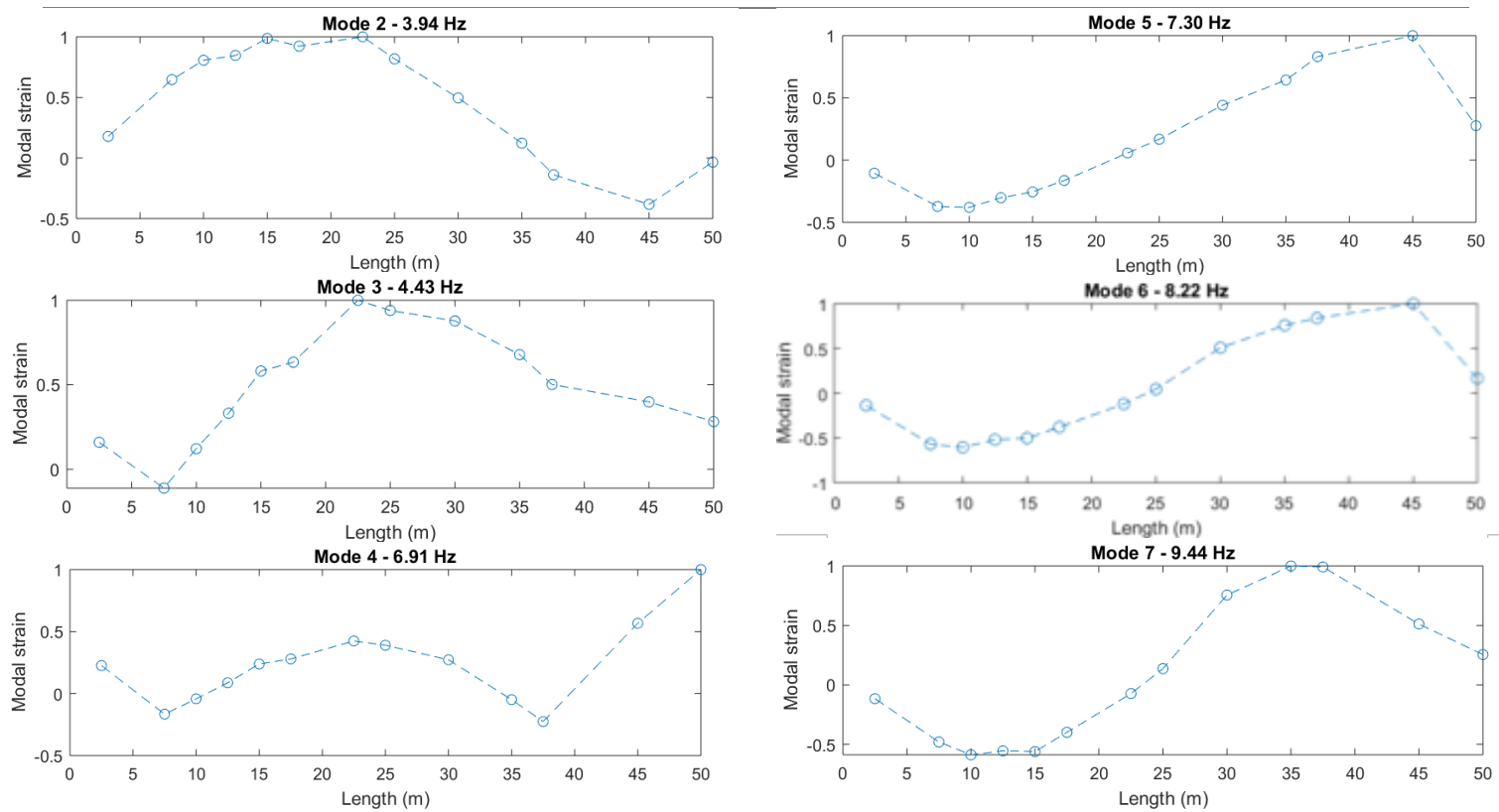

Figure 16: The modal strain shape of the first lateral mode, the first torsional mode, the first bending of the deck mode and of mode 5, 6 and 7 measured with strain amplifying transducers under ambient excitation.

\section{Conclusions}

If vibration-based structural health monitoring of civil structures is enhanced with strain measurements a resolution of the order of $0.1 \mu \varepsilon$ or better is required. To enable such measurements using conventional broadband fibre Bragg grating interrogators, dedicated strain amplifying transducers providing for a pre-determined strain amplification factor can be a viable option.

The first step towards testing the ability to determine modal strains under very low excitation level using strain amplifying transducers was to equip a $5 \mathrm{~m}$ long prestressed concrete beam with 32 FBGs on transducers, as well as with 20 regular directly mounted FBGs. We carried out two dynamic tests with excitation force amplitudes of $10 \mathrm{~N}$ and $130 \mathrm{~N}$. For the first test the actual strain level on the beam did not exceed $0.06 \mu \varepsilon$ but we nevertheless identified the three first bending modes with MAC values 
of $0.859,0.989$ and 0.940 , respectively. With the clamped FBG sensors, we could only identify two bending modes with MAC values of 0.113 and 0.577 , respectively. For the second test the actual strain level on the beam was about $0.8 \mu \varepsilon$, and we successfully identified the three first bending modes using our transducers with MAC values above 0.95 . With the clamped FBG sensors experiencing strain levels just within the range of the strain resolution, we could also identify three bending modes but with clearly lower MAC values of $0.559,0.705$ and 0.929 . With that, we have demonstrated that it is possible to identify strain mode at strain amplitudes of $0.1 \mu \varepsilon$ with FBG sensors mounted on strain amplifying transducers and using FBG interrogator with wavelength resolution of $1 \mathrm{pm}$.

The next step was a field test on a high-speed railway viaduct. Therefore, we equipped one span with 20 FBG sensors on transducers with a strain amplification of 80. From a dynamic test 6 strain modes of the viaduct were obtained under extremely low ambient excitation level.

We conclude that FBGs mounted on dedicated low-cost strain amplifying transducers can be potentially applied in combination with conventional broadband interrogation equipment for vibration-based structural health monitoring of civil concrete structures in ambient conditions yielding dynamic strain level amplitudes below $1 \mu \varepsilon$. However, it should also be underlined that the obtained modal strain shapes in both experiments do not fit perfectly with the calculated modes. This may be due to a variation in the actual strain amplification value between the different strain transducers once installed. Therefore, additional tests should be carried out on the fixation of the transducers to the structure to improve the reproducibility of the results.

\section{Acknowledgements}

This research has been performed as part of project G099014N: "Robust vibration-based damage identification with a novel high-accuracy strain measurement system" funded by the Research Foundation - Flanders (FWO). The authors also would also like to acknowledge financial support from the Methusalem and Hercules Foundations.

\section{References}

[1] Reynders E., "System Identification Methods for (Operational) Modal Analysis : review and comparison," Arch. Comput. Methods Eng., vol. 19, no. 1, 2012.

[2] Fan W. and Qiao P., "Vibration-based damage identification methods: a review and comparative study," Struct. Heal. Monit., vol. 10, no. 1, 2011.

[3] Peeters B. and De Roeck G., "One-year monitoring of the Z 24-Bridge: environmental effects versus damage events," Earthq. Eng. Struct. Dyn., vol. 30, pp. 149-171, 2001.

[4] Deraemaeker A., Reynders E., De Roeck G., and Kullaa J., "Vibration-based structural health monitoring using output-only measurements under changing environment," Mechanical Systems and Signal Processing, vol. 22, pp. 34-56, 2008.

[5] Unger J. F., Teughels A., and De Roeck G., "Damage Detection of a Prestressed Concrete Beam Using Modal Strains," Journal of Structural Engineering, vol. 131, no. 9, pp. 1456-1463, 2006.

[6] Anastasopoulos D., De Smedt M., Vandewalle L., De Roeck G., and Reynders E. P. B., "Damage identification using modal strains identified from operational fiber-optic Bragg grating data," Struct. Heal. Monit., vol. 17, no. 6, pp. 1441-1459, 2018.

[7] Luis F., Peeters B., and Lau J., "The use of strain gauges in vibration-based damage detection," in 11th International Conference on Damage Assessment of Structures, 2015.

[8] Glišić B. and Inaudi D., Fibre Optic Methods for Structural Health Monitoring. John Wiley \& Sons, 2007. 
[9] Fan S., Ren L., Li H., and Song B., "Real-Time Monitoring and Early Warning Method Utilizing FBG Sensors in the Retrofitting Process of Structures," in International Journal of Distributed Sensor Networks, 2015.

[10] Chan T. H. T. et al., "Fiber Bragg grating sensors for structural health monitoring of Tsing Ma bridge: Background and experimental observation," Eng. Struct., vol. 28, no. 5, pp. 648-659, 2006.

[11] Schulz W. L., Conte J. P., and Udd E., "Long-gage fiber optic Bragg grating strain sensors to monitor civil structures," Blue Road Res., vol. 4330, pp. 56-65, 2001.

[12] Anastasopoulos D. et al., "Identification of modal strains using sub-microstrain FBG data and a novel wavelength-shift detection algorithm," Mech. Syst. Signal Process., vol. 86, pp. 58-74, 2017.

[13] Nawrot U. et al., "Development of a mechanical strain amplifying transducer with Bragg grating sensor for low-amplitude strain sensing," Smart Mater. Struct., vol. 26, no. 7, 2017.

[14] "FBGS." [Online]. Available: https://www.fbgs.com. [Accessed: 03-Sep-2017].

[15] “COMSOL Multiphysics.” [Online]. Available: https://www.comsol.com. [Accessed: 03-Sep-2017].

[16] “HBM.” [Online]. Available: https://www.hbm.com. [Accessed: 03-Sep-2018].

[17] ASTM C215-02, Standard Test Method for Fundamental Transverse, Longitudinal, and Torsional Resonant Frequencies of Concrete Specimens, ASTM International, West Conshohocken, PA, 2019, www.astm.org

[18] Reynders E., Schevenels M., and De Roeck G., "MACEC 3.3: A Matlab Toolbox for Experimental and Operational Modal Analysis," Report BWM-2014-06, 2014.

[19] Reynders E., Pintelon R., and De Roeck G., "Uncertainty bounds on modal parameters obtained from stochastic subspace identification," Mech. Syst. Signal Process., vol. 22, no. 4, pp. 948-969, 2008.

[20] Peeters B. and De Roeck G., "Reference-based stochastic subspace identification for output-only modal analysis," Mech. Syst. Signal Process, vol. 13, pp. 855-878, 1999.

[21] “Arbre Viaduct." [Online]. Available: https://structurae.net. [Accessed: 22-Jan-2019].

[22] “FAZ Technology." [Online]. Available: http://www.faztechnology.com. 